\title{
Uso de modelagem 4D e Building Information Modeling na gestão de sistemas de produção em empreendimentos de construção
}

\author{
The use of 4D modeling and Building Information \\ Modeling for the management of production systems in \\ construction projects
}

\section{Clarissa Notariano Biotto \\ Carlos Torres Formoso \\ Eduardo Luis Isatto}

\section{Resumo}

$\mathbf{U}$

m modelo BIM é uma representação digital de uma edificação, combinando informações tridimensionais e não-geométricas. Uma vez associado com as durações de atividades ou etapas da construção, o modelo resultante (modelo BIM 4D) pode ser utilizado para projetar e planejar sistemas de produção de empreendimentos de construção através da visualização do plano de execução da obra. Em geral, os estudos sobre o uso combinado da modelagem 4D e BIM realizados até este momento tem tido como foco decisões acerca do planejamento de processos construtivos específicos, dedicando pouca atenção quanto à implementação de modelos BIM 4D na gestão de sistemas de produção no contexto organizacional de empresas de construção. $\mathrm{O}$ presente trabalho tem como objetivo propor um método para apoiar a gestão de sistemas de produção em empreendimentos de construção através do uso da modelagem BIM 4D para o projeto do sistema de produção e planejamento da produção. Esta pesquisa adota a design science research como modo de produção de conhecimento, envolvendo quatro estudos empíricos em três empresas de construção de edificações residenciais. A principal contribuição da pesquisa consiste no método para uso de BIM 4D na gestão de sistemas de produção em empreendimentos de construção, além da identificação de um conjunto de benefícios que podem ser esperados a partir do uso dos modelos BIM 4D na gestão de sistemas de produção no contexto de empreendimentos de construção.

Palavras-chaves: BIM. Modelagem 4D. Planejamento. Gestão da produção. Sistemas de produção.

Clarissa Notariano Biotto SIPPRO - Soluções de Planejamento da Produção Fortaleza - CE - Brasil

Carlos Torres Formoso Universidade Federal do Rio Grande do Sul Porto Alegre - RS - Brasil

Eduardo Luis Isatto Universidade Federal do Rio Grande do Sul Porto Alegre - RS - Brasil

Recebido em 01/04/13 Aceito em 01/04/15

\begin{abstract}
A BIM model is a digital representation of a building, combining tridimensional and non-geometric information. Once associated with the duration of tasks or construction phases, the derived model (a BIM 4D model) can support the design and planning of production systems in construction projects through the visualization of the construction plans. In general, previous studies on the combined use of 4D modelling and BIM have focused on specific construction processes, paying very little attention to the implementation of BIM 4D models in the design and planning of production systems in the organizational context of construction companies. This research study aims to devise a method to support the management of production systems in construction projects through the use of BIM 4D modelling in production system design and production planning. The design science research approach was adopted in this investigation, comprising of four empirical studies performed in three residential building construction companies. The main contribution of this study is a method for using BIM 4D in the management of production systems in construction projects, as well as the identification of a set of benefits that can be expected from the use of BIM $4 D$ in production management in the context of construction projects.

Keywords: BIM. 4D modeling. Planning. Production management.
\end{abstract}




\section{Introdução}

Diferentemente das indústrias de manufatura, a construção apresenta peculiaridades que afetam significativamente a gestão do sistema de produção. Segundo Koskela e Ballard (2003), o caráter único dos produtos e a natureza temporária da organização criada para sua produção figuram entre as diferenças mais marcantes entre a construção civil e as indústrias de manufatura. Devido ao caráter estacionário do empreendimento, os diversos agentes se movimentam pelo produto e alteram as condições existentes, sendo o leiaute alterado à medida que vai sendo construído (WEBB; HAUPT, 2005).

A complexidade envolvida na construção civil é elevada, uma vez que cada decisão afeta um grande número de outras decisões (PAPAMICHAEL, 1999), demandando ações, métodos, técnicas e ferramentas apropriados para gerenciá-los com sucesso (BACCARINI, 1996). O uso de técnicas de planejamento da produção (como o diagrama de precedência e a linha de balanço) e ferramentas de visualização (planilha de dimensionamento de capacidade de recursos) específicas é demandado pelo contexto particular da construção civil (SCHRAMM; COSTA; FORMOSO, 2006; RODRIGUES, 2006). Contudo, uma deficiência marcante dessas técnicas e ferramentas é o fato de não proporcionarem visualização espacial da construção ao longo de sua execução.

Tal visualização passou a ser possível a partir de modelos 4D, que consistem basicamente em uma combinação do modelo geométrico digital do empreendimento (o modelo 3D, representando sua dimensão espacial) e as informações originárias do planejamento de sua construção (representando sua dimensão temporal) (RISCHMOLLER; ALARCON, 2002; RILEY, 2005; KUNZ; FISCHER, 2011). No entanto, o custo e o esforço envolvidos na criação e atualização de tais modelos constituíram em barreiras significativas à disseminação do uso de 4D no setor (KHATIB; CHILESHE; SLOAN, 2007). Mais recentemente, a crescente adoção da tecnologia Building Information Modeling (BIM) pelas empresas de construção tem sinalizado um aumento no interesse pelo uso da modelagem 4D para a gestão da produção. Sendo representações de edificações ricas em dados, a partir das quais visões e informações necessárias a diferentes usuários podem ser extraídas e analisadas simultaneamente e de forma coordenada, os modelos BIM apresentam uma oportunidade para tomar decisões e melhorar o processo de construção (ASSOCIED..., 2011). De fato, em recente estudo que contou com a participação de 727 construtores de dez países, a organização McGraw Hill Construction constatou que o uso de BIM 4D figura entre as três atividades pré-construção consideradas mais importantes por $29 \%$ dos entrevistados (MCGRAW HILL, 2014).

Eadie et al. (2013) conduziram estudo para identificar e analisar os motivos que conduzem as empresas à adoção de BIM. Diversos dos motivos identificados envolvem em maior ou menor grau o uso de modelagem 4D, entre eles a identificação prévia de conflitos de projeto (clash detection), o estudo da sequência de execução da construção e a comunicação com as equipes envolvidas diretamente na execução. Como Eastman et al. (2011) salientam, o fato de as informações geométricas já se encontrarem incluídas nos modelos BIM faz com que elas possam ser utilizadas diretamente na geração de modelos 4D, simplificando enormemente esse processo. Zhou et al. (2009) apontam ainda outras vantagens no uso de modelos 4D gerados a partir de modelos BIM, ao afirmar que isso pode ser especialmente útil para contornar algumas dificuldades encontradas na utilização interativa da modelagem $4 \mathrm{D}$, visando a apoiar a tomada de decisão durante o processo de planejamento do empreendimento. Estes mesmos autores ressaltam a necessidade de mecanismos mais confiáveis para a identificação e a eliminação de conflitos durante a simulação, e da correta manipulação e associação entre os níveis de detalhe do cronograma e dos componentes do modelo 3D.

Entretanto, o esforço envolvido na mudança e atualização dos modelos 4D faz com que a utilização deles tenha tradicionalmente se restringido aos estágios iniciais dos empreendimentos, ainda na fase de projeto e ao planejamento pré-construção, sem buscar apoiar diretamente a gestão da produção (EASTMAN et al., 2011; SACKS; RADOSAVLJEVIC; BARAK, 2010). Além disso, como a criação de tais modelos está normalmente associada à utilização de ferramentas tradicionais de planejamento, tais como o Método do Caminho Crítico (CPM) e diagramas de Gantt (HAYMAKER; FISCHER, 2001; ZHOU et al., 2009), os modelos resultantes acabam por não levar em consideração aspectos considerados críticos para o desempenho do sistema de produção, tais como as instalações provisórias, equipamentos, fluxos físicos ou locais de estoques de materiais. Em decorrência dessas limitações, poucos trabalhos descritos na literatura abordam a implementação de modelos 4D no

80 Biotto, C. N.; Formoso, C. T.; Isatto, E. L. 
contexto organizacional de empresas de construção.

No Brasil, tem sido crescente nos últimos anos o número de iniciativas acadêmicas relacionadas ao uso de BIM tanto no ensino (BARISON; SANTOS, 2012; RUSCHEL; ANDRADE; MORAIS, 2013) como na pesquisa (CHECCUCCI; PEREIRA; AMORIM， 2013; RUSCHEL, 2014). Entretanto, há um número muito pequeno de publicações que relatam resultados de pesquisas sobre o uso de modelos BIM 4D no ambiente organizacional.

Uma das publicações que tratam da implementação de BIM em projetos de construção é o BIM Project Execution Planning Guide, elaborado pela Penn State University (MESSNER et al., 2010). De caráter essencialmente prescritivo, a publicação fornece um método para integrar a implementação de BIM ao processo de execução do empreendimento, definindo o escopo da implementação de BIM no projeto, identificando o fluxo do processo das tarefas relacionadas, definindo as trocas de informações entre as partes envolvidas e descrevendo a infraestrutura necessária ao projeto e à empresa para suportar a implementação. Nele a modelagem 4D é abordada como uma ferramenta de suporte ao planejamento do empreendimento, sem, porém, discutir aspectos envolvendo sua integração aos modelos e técnicas de planejamento e controle da produção envolvidos.

Em que pese a tal importante contribuição, é possível afirmar que há muito poucos estudos relacionando a implementação de modelagem 4D à gestão dos sistemas de produção em empreendimentos a partir do emprego de abordagens de gestão da produção mais modernas, tais como a Produção Enxuta (Lean Production). A Produção Enxuta tem origem na indústria automotiva, e, ao longo dos últimos vinte anos, tem havido um esforço muito grande no sentido de adaptá-la ao setor da construção, com resultados promissores (KOSKELA, 2000), particularmente com relação ao processo de planejamento e controle da produção através da aplicação do Sistema Last Planner de Controle da Produção (BALLARD, 2000). De fato, há evidências de que potencialmente existe uma grande sinergia entre as práticas da Lean Production e o uso de BIM (SACKS; RADOSAVLJEVIC; BARAK, 2010).
$\mathrm{Na}$ gestão de sistemas de produção, as decisões podem ser divididas em três conjuntos de ações (KOSKELA; BALLARD, 2003):

(a) concepção do sistema de produção;

(b) operação do sistema de produção, que pode ser dividida em planejamento e controle; e

(c) melhoria do sistema de produção.

O presente trabalho tem como foco dois desses processos gerenciais, os quais apresentam grande potencial de utilização dos modelos BIM 4D: o projeto do sistema de produção (PSP), que é parte de sua concepção; e o planejamento e controle da produção (PCP), um processo gerencial que tem grande impacto na operação e na melhora de sistemas de produção. O PSP é a primeira tarefa gerencial a ser realizada no início de qualquer esforço produtivo (BALLARD et al., 2001), enquanto o PCP ocorre durante a realização do ato produtivo, tendo um importante papel na melhoria do desempenho do sistema de produção (KOSKELA; BALLARD, 2003).

Tendo em vista o caráter recente da adoção de BIM pelas empresas do setor e o conhecimento ainda incipiente acerca do potencial representado pelo uso de modelos 4D como ferramenta de apoio à gestão do sistema de produção em empreendimentos de construção, o presente trabalho tem por objetivos:

(a) apontar os principais benefícios do uso de modelos BIM 4D como mais uma ferramenta de apoio à gestão do sistema de produção; e

(b) propor um método para o uso da modelagem BIM 4D para apoiar a tomada de decisões durante o projeto do sistema e o planejamento da produção.

Este estudo faz parte da Rede de Pesquisa TICHIS ${ }^{1}$ (Tecnologia da Informação e Comunicação em Habitações de Interesse Social), cujo objetivo consiste em desenvolver soluções inovadoras em tecnologia da informação e comunicação aplicadas à construção e arquitetura, visando à melhoria da qualidade e produtividade do segmento de habitação de interesse social. O presente estudo tem como foco empreendimentos habitacionais voltados para o mercado de baixa renda, com características repetitivas.

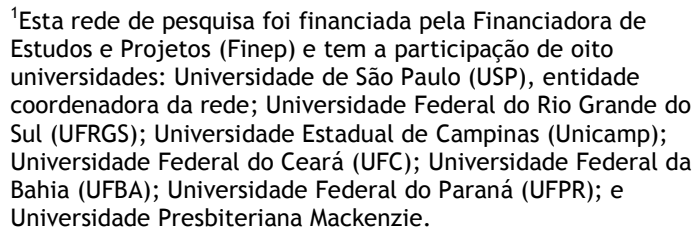

${ }^{1}$ Esta rede de pesquisa foi financiada pela Financiadora de Estudos e Projetos (Finep) e tem a participação de oito universidades: Universidade de São Paulo (USP), entidade coordenadora da rede; Universidade Federal do Rio Grande do Sul (UFRGS); Universidade Estadual de Campinas (Unicamp); Universidade Federal do Ceará (UFC); Universidade Federal da Bahia (UFBA); Universidade Federal do Paraná (UFPR); e Universidade Presbiteriana Mackenzie. 


\section{Gestão de sistemas de produção \\ Planejamento e controle da produção}

Segundo Laufer e Tucker (1987), o planejamento tem por objetivo responder às seguintes questões: o que será feito (atividades), como as atividades deverão ser executadas (métodos), quem realizará cada uma das atividades e com quais meios (recursos), e quando cada atividade deverá ser executada (momento e sequência de execução).

O PCP desempenha um papel crítico na execução de um empreendimento de construção. Segundo Ballard e Howell (1998), um PCP adequado tem como consequência um aumento da confiabilidade em termos de prazos e da produtividade, na medida em que estabelece um sequenciamento adequado do trabalho, dimensiona as equipes de mão de obra e os equipamentos conforme o trabalho a ser realizado, e coordena as múltiplas atividades interdependentes (BALLARD; HOWELL, 1998).

Durante o planejamento da produção podem ser empregadas técnicas específicas para a programação de projetos, entre elas as técnicas da rede de precedência (PERT e CPM) e a técnica da linha de balanço (Line of Balance, ou LOB). A técnica do CPM constitui a base da maioria dos sistemas computacionais para planejamento e controle de empreendimentos, tais como Microsoft Project $^{\circledR}$, Primavera ${ }^{\circledR}$ e outros.

Já a técnica da linha de balanço tem sua aplicação associada a projetos de natureza repetitiva, sendo as unidades repetitivas (denominadas de unidadebase) executadas múltiplas vezes segundo uma taxa de produção. Tal taxa de produção constituise em um parâmetro crítico em obras repetitivas segundo Arditi, Tokdemir e Suh (2002), uma vez que a adoção de uma única taxa de produção para todas as atividades pode diminuir a ociosidade das equipes e reduzir consideravelmente os prazos de execução do empreendimento. A programação através da técnica da linha de balanço também permite determinar a necessidade de recursos humanos durante a realização do projeto, através da utilização de histograma de recursos, derivado do gráfico da linha de balanço.

Em função da elevada incerteza que existe no ambiente da construção civil, os sistemas de planejamento e controle da produção devem ser divididos em diferentes níveis hierárquicos (LAUFER; TUCKER, 1987). Esta é a abordagem do sistema Last Planner, no qual normalmente são utilizados três níveis hierárquicos:
(a) longo prazo (master planning);
(b) médio prazo (look-ahead planning); e
(c) curto prazo (commitment planning).

Este sistema utiliza um mecanismo de proteção da produção contra a variabilidade (denominado de shielding production) no planejamento do curto prazo, e a identificação e remoção sistemática de restrições, o que contribui para melhorar a confiabilidade dos fluxos de trabalho, no nível de médio prazo (BALLARD, 2000). Faz parte do Last Planner um conjunto de indicadores de desempenho, sendo o principal deles o percentual de pacotes concluídos (PPC), utilizado para monitorar a eficácia do processo de planejamento (BALLARD, 2000).

\section{Projeto do sistema de produção}

O PSP tem por objetivo discutir e traduzir a estratégia de produção desejada em um conjunto de decisões sobre o sistema de produção no início de qualquer esforço produtivo, formando assim uma estrutura que serve de referência para gerenciar diferentes atividades (SCHRAMM; COSTA; FORMOSO, 2006). Existem evidências de que tais decisões, quando tomadas previamente à execução, contribuem para a mitigação dos efeitos da variabilidade e incerteza inerentes aos sistemas de produção (KOSKELA, 2000; BALLARD et al., 2001), além de contribuírem na melhoria do desempenho do PCP e na busca pela melhoria contínua do empreendimento (SCHRAMM; COSTA; FORMOSO, 2006).

Segundo Gaither e Frazier (2001), o PSP envolve planejar os processos, os produtos ou serviços, a tecnologia empregada e o mercado, para que se possa desenvolver um plano detalhado com a finalidade de produzir produtos e serviços. Durante a elaboração do projeto do sistema de produção, devem-se considerar alternativas de organização da produção visando a escolher a estratégia mais adequada para se alcançarem os resultados desejados (MEREDITH; SHAFER, 2002).

As decisões tomadas durante a elaboração do PSP envolvem a definição do nível de integração vertical, nível da capacidade produtiva, arranjo físico e fluxos de trabalho, sincronização entre processos de produção, e projeto dos processos de produção (SCHRAMM; COSTA; FORMOSO, 2006). Tais decisões são interdependentes, e se uma delas for alterada as demais normalmente são atingidas (MEREDITH; SHAFER, 2002).

Schramm, Costa e Formoso (2006) sugerem que a elaboração do PSP de um empreendimento deva empregar simultaneamente diversas ferramentas, visando a prover dispositivos visuais que facilitem

82 Biotto, C. N.; Formoso, C. T.; Isatto, E. L. 
a tomada de decisão pela equipe de planejamento. Além da rede de precedência de atividades, da LOB e do histograma de recursos, anteriormente mencionados, tais autores recomendam o uso da planilha de dimensionamento da capacidade de produção e do diagrama de sincronia. A planilha de dimensionamento da capacidade de produção formaliza os recursos de produção necessários à execução de cada atividade da rede de precedência, apresentando informações acerca das equipes de mão de obra, equipamentos, durações das atividades, seus lotes de produção e de transferência, e atividades predecessoras. Já o diagrama de sincronia consiste basicamente em um gráfico de barras de localidade por tempo, no qual se visualiza o fluxo de trabalho de equipes, buscando a melhor utilização de recursos para os processos críticos.

Schramm, Costa e Formoso (2006) propõem um modelo de PSP para empreendimentos que possuam características repetitivas (Figura 1). Esse modelo é composto de seis fases, que definem as principais decisões do PSP. Algumas fases adotam como unidade de análise a unidade-base (por exemplo, uma casa, um pavimento ou um apartamento), enquanto outras tratam do empreendimento como um todo. As alterações nas decisões estabelecidas em qualquer uma dessas etapas repercutem nas demais etapas de decisões do modelo, fazendo com que, após a tomada a decisão, seja realizada a revisão no sentido contrário das etapas (SCHRAMM; COSTA; FORMOSO, 2006).

\section{PCP e o PSP na gestão do sistema de produção}

Os limites entre as atividades que compõem o escopo do PSP e do PCP são bastante tênues (SCHRAMM; COSTA; FORMOSO, 2006), particularmente em relação ao plano de longo prazo do empreendimento (SCHRAMM, 2009). Enquanto o planejamento da produção dita o que será produzido, quando e por quem, o PSP tem por objetivo disponibilizar a infraestrutura necessária para viabilizar tal produção. Assim, segundo Schramm, Costa e Formoso (2006), o plano de longo prazo pode ser considerado um dos resultados do PSP, na medida em que este estabelece um estado futuro a ser alcançado pela função produção do empreendimento, esta última obrigatoriamente condicionada às restrições impostas pelo sistema de produção.

Não obstante a necessidade da realização do PSP antes do início efetivo da produção, situações imprevistas ocorridas durante a execução da obra poderão demandar a revisão posterior de algumas das decisões tomadas. Assim, Rodrigues (2006) e Schramm (2009) ressaltam que as mesmas ferramentas utilizadas durante a elaboração do PSP podem se mostrar necessárias posteriormente, durante a execução da obra, visando a auxiliar na avaliação de alternativas de planos de recuperação de atrasos na obra.

Figura 1 - Modelo de elaboração do PSP para EHIS

\section{Projeto do sistema de produção}

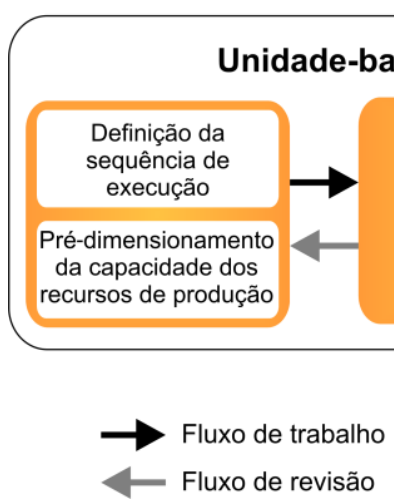

Fonte: Schramm, Costa e Formoso (2006, p. 6). fluxos de trabalho

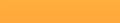

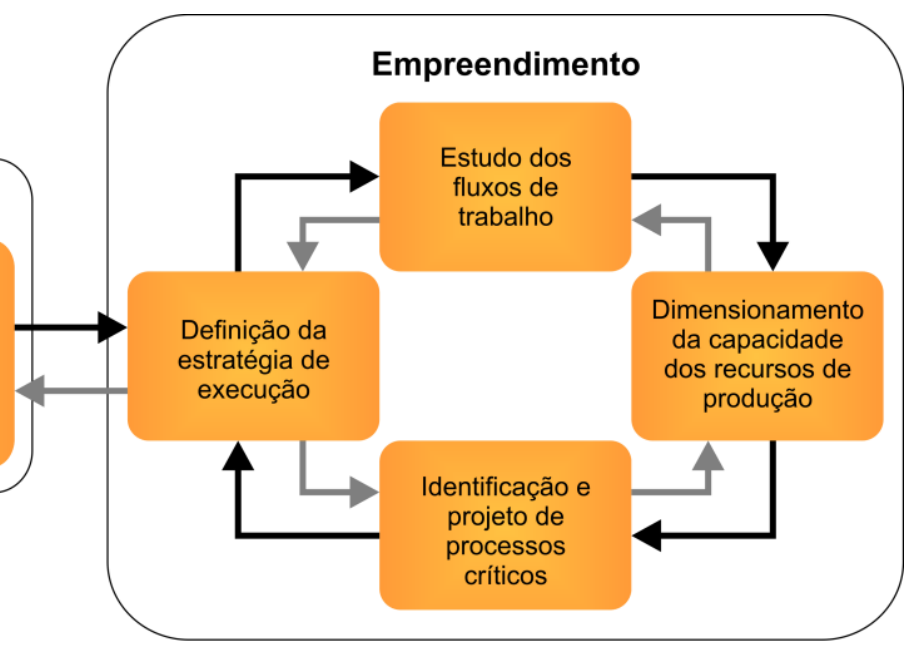




\section{Building Information Modeling e modelagem 4D}

Um modelo 4D de uma edificação consiste em uma associação de seu modelo 3D ao tempo: as tarefas que compõem o cronograma da construção são associadas aos componentes ou partes do modelo 3D, permitindo, assim, a visualização da sequência de execução, de forma a contribuir para o entendimento do processo de produção por parte dos envolvidos em sua gestão e a apoiar a tomada de decisão (KYMMEL, 2008). Segundo Eastman et al. (2011), a modelagem 4D não é algo recente na construção, sendo utilizada já há algumas décadas. Por exemplo, Collier e Fischer (1995) relataram a utilização de modelos 4D para comunicar, planejar a logística e coordenar equipes na obra de ampliação de um hospital.

No entanto, a utilização da modelagem 4D pelas empresas não é algo trivial. No caso de sistemas CAD, as associações entre componentes e atividades são trabalhosas, tornando difícil atualizar as datas ou analisar possíveis cenários alternativos, em decorrência do grande esforço necessário.

Segundo Eastman et al. (2011), essa é uma das razões pelas quais o uso da modelagem $4 \mathrm{D}$ tem sido historicamente restrita aos estágios iniciais de projeto, quando a visualização do empreendimento é necessária para o cliente ou devido a algum interveniente externo ao empreendimento.

Em sua forma mais simples, um modelo 4D pode ser elaborado simplesmente mediante a associação das partes de um modelo 3D (construído a partir de CAD ou outros) às datas de sua construção ou demolição. Agrupando-os segundo o período da obra, sua visualização pode ser ativada ou desativada com a utilização de filtros, simulando o progresso da obra. $\mathrm{O}$ uso de cores diferentes pode também ser utilizado para representar diferentes estágios da construção. Com o intuito de melhorar a visualização de modelos CAD 4D, Benjaoran e Bhokha (2009) detectaram as limitações dessa ferramenta e propuseram o uso de diferentes propriedades visuais para os objetos CAD 3D como cor, espessura de linha e tipo de linha - para representar os diversos status das atividades.

Nos anos recentes, a modelagem 4D passou a ser impulsionada pela disseminação dos sistemas baseados na tecnologia BIM. Os recursos de interoperabilidade e a possibilidade de centralização da informação, oportunizados pela tecnologia BIM, diminuem a necessidade de coleta e mudança das informações, resultando em aumento da velocidade e precisão das informações transmitidas, na possibilidade de automatização de verificações e análises, bem como ao suporte às atividades de operação e manutenção (GENERAL..., 2007; EASTMAN et al., 2011).

Com a introdução dos modelos BIM, a modelagem 4D beneficia-se pelo fato de que tais modelos possuem não só as informações geométricas da construção (ou seja, o modelo 3D), mas podem conter outras informações relativas ao processo de produção, tais como índices de produtividade, custos, natureza dos recursos necessários. Assim, as alterações realizadas tanto no modelo 3D como no plano podem ser automaticamente atualizadas no modelo 4D. Isso torna possível aos planejadores criar, revisar e editar os modelos 4D com mais frequência, favorecendo a elaboração de planos mais adequados, o que possibilita aos modelos desempenhar papel ativo na avaliação de sequências de construção, inclusive considerando os componentes temporários da construção (instalações de canteiro e equipamentos) (EASTMAN et al., 2011).

Choi et al. (2014) associaram aos objetos do modelo BIM 4D informações sobre o espaço de trabalho necessário para sua construção, facilitando o estudo de interferências espaciais entre equipamentos e homens nos locais de trabalho.

Aplicativos 4D são programas desenvolvidos especificamente visando à criação e à visualização desses modelos através de animações 4D, estas últimas na forma de filmes ou simulações virtuais do cronograma (EASTMAN et al., 2011). Os aplicativos BIM 4D, por sua vez, são aplicativos 4D que possuem a capacidade de utilizar modelos BIM como fonte das informações associadas com a geometria da edificação.

Diversas recomendações podem ser encontradas na literatura no que diz respeito ao processo de modelagem 4D. Coble, Blatter e Agaj (2005) ressaltam a importância de se definir claramente o usuário do modelo $4 \mathrm{D}$, que pode ser o setor de planejamento, o setor de projetos ou, ainda, as equipes presentes no canteiro de obra, incluindo o engenheiro residente e encarregados. Já Fischer, Haymaker e Liston (2005) chamam a atenção para a definição do escopo do modelo 4D, a partir da identificação por parte das equipes do empreendimento dos problemas a serem resolvidos a partir do uso de modelos 4D. Segundo os mesmos autores, a clara definição desses objetivos tem implicações na escolha das pessoas a serem envolvidas no esforço da modelagem.

Uma decisão importante no processo de modelagem é o grau de desenvolvimento do modelo 4D, o qual afeta diretamente o nível de detalhamento do plano de execução e do modelo 
3D a ele associados. A decisão acerca do nível adequado de detalhe deve levar em conta os objetivos dos usuários do modelo (EASTMAN et al., 2011), as respostas que se espera que ele forneça (FISCHER; HAYMAKER; LISTON, 2005) e os impactos e benefícios esperados a partir de sua utilização (LEITE et al., 2011).

Com relação à definição do aplicativo de modelagem 4D, Eastman et al. (2011) chamam a atenção para diversas características que devem ser observadas, em função do escopo previsto da modelagem, tais como as extensões de arquivos, informações de objetos e formatos de planos que podem ser importados, a combinação e atualização automática dos modelos, e a possibilidade de reorganização e divisão dos componentes dos modelos depois de importados.

Fischer, Haymaker e Liston (2005) oferecem ainda recomendações acerca da definição do responsável pela construção do modelo 4D. Tais autores sugerem que essa responsabilidade deve ser da empresa que executa o empreendimento, pois, ao contrário dos projetistas e modeladores, ela desempenha papel fundamental na especificação das informações que deverão compor o modelo e de seu nível de detalhe. Zhou et al. (2009) sugerem o uso de uma abordagem colaborativa para a modelagem 4D. Com o emprego de um sistema servidor-cliente, os usuários combinam de maneira interativa o modelo 3D com um plano do empreendimento, gerado a partir de um aplicativo de planejamento de projetos, gerando cenários que são simulados através do BIM 4D. Com base nos resultados, o cenário é aprovado ou novas alterações são propostas.

\section{Método de pesquisa}

O presente trabalho enquadra-se no modo de produção de conhecimento denominado de pesquisa construtiva (constructive research), também denominado de ciências do design (design science research) (KASANEN; LUKKA; SIITONEN, 1993; LUKKA, 2003), cujo objetivo consiste em produzir um artefato inovador com a intenção de resolver problemas encontrados no mundo real, e também fazer teorias para determinada área do conhecimento (LUKKA, 2003).

A pesquisa construtiva tem como principais atividades construir e avaliar o artefato (MARCH; SMITH, 1995). No presente trabalho, o método para o uso da modelagem BIM 4D para auxiliar a tomada de decisão no projeto e planejamento de sistemas de produção corresponde ao artefato desenvolvido.

A pesquisa se desenvolveu em quatro grandes fases, conforme mostra a Figura 2:
(a) revisão bibliográfica;
(b) fase exploratória;
(c) fase de desenvolvimento; e
(d) fase de consolidação.

A primeira fase da pesquisa foi marcada pela compreensão do problema real enfrentado por empresas construtoras e pela compreensão da lacuna de conhecimento, com base na revisão inicial de literatura, na qual se buscou compreender em profundidade os temas de modelagem 4D, BIM e gestão da produção. Essa revisão de literatura perdurou por todo o desenvolvimento deste trabalho.

Figura 2 - Delineamento da pesquisa

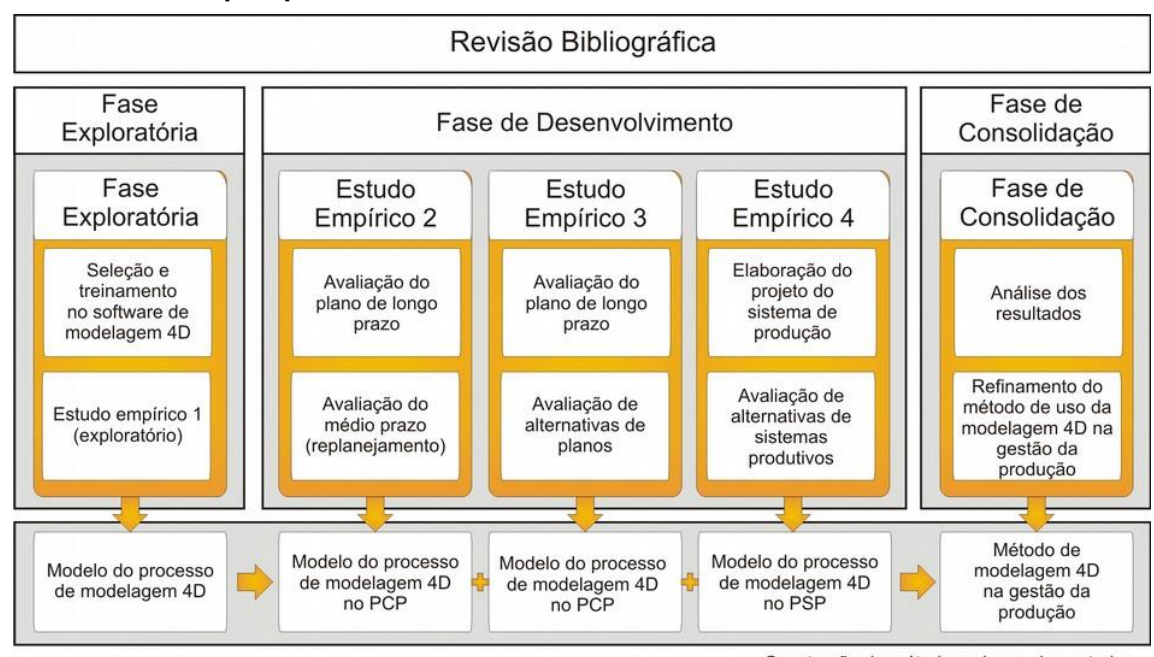

Construção do método ao longo dos estudos 
A segunda fase, de caráter exploratório, durou cinco meses e contemplou as seguintes tarefas:

(a) seleção do aplicativo de simulação 4D (Autodesk Navisworks Manage);

(b) treinamento de um dos pesquisadores no aplicativo escolhido; e

(c) estudo empírico 1 (EE1).

Neste primeiro estudo fez-se a primeira modelagem BIM 4D para apoiar o planejamento da obra, simulando planos de longo prazo, sendo também elaborados uma linha de balanço e o projeto de leiaute de canteiro. Como produto final desta fase foi proposta a primeira versão do método para modelagem BIM 4D.

A terceira fase, de desenvolvimento, compreendeu três estudos empíricos (EE2, EE3 e EE4), nos quais a modelagem BIM 4D foi utilizada para apoiar a tomada de decisão referente à gestão da produção em diferentes situações. Assim, ao longo da realização dos estudos, o método inicialmente proposto na fase exploratória foi progressivamente aprimorado.

O EE2 teve como principal objetivo simular o planejamento da produção com o uso de modelos BIM 4D, e sua utilização como suporte à tomada de decisão fornecendo cenários esperados em decorrência de possíveis alternativas de mudança na sequência de ataque de realização do serviço de revestimento externo de fachadas. Para isso, a modelagem BIM 4D foi utilizada em conjunto com ferramentas de planejamento e controle.

No EE3 buscou-se visualizar a sequência executiva na unidade-base e o plano de ataque do empreendimento, e simular alternativas dele com modelos BIM 4D, conforme a empresa solicitava. Diferentemente dos empreendimentos dos demais estudos de caso, o Empreendimento L3 consistia num empreendimento horizontal, em que as distâncias e a sequência de ataque exercem forte influência sobre o esforço de transporte e movimentação.

Já no EE4 o foco do estudo foi elaborar o PSP junto com os participantes da empresa e escolher a melhor alternativa de equipamentos e plano de ataque, conforme disponibilidade de mão de obra e ritmo de vendas.

Todos os estudos realizados incluíram visitas de um dos pesquisadores às obras e escritórios das empresas para a coleta dos dados necessários à elaboração dos modelos BIM 4D, a produção de um ou mais cenários com base em diferentes configurações do sistema de produção e a apresentação dos resultados às empresas. As fontes de evidências adotadas foram:

(a) entrevistas abertas, semiestruturadas e estruturadas, desenvolvidas com os diretores, engenheiros de obra e planejamento das empresas;

(b) observação participante, a qual ocorreu durante as reuniões de planejamento e de elaboração do PSP e PCP;

(c) observação direta e registro fotográfico das obras e escritórios; e

(d) análise de documentos, como projetos, planilhas e cronogramas de obra.

Ao final dos estudos empíricos procedeu-se à quarta fase, quando foi realizada uma análise conjunta dos resultados obtidos e proposto $\mathrm{o}$ método para o uso da modelagem BIM 4D no apoio à tomada de decisão no projeto do sistema e no planejamento da produção em sua forma final, o qual foi avaliado com base nos constructos utilidade e facilidade de uso.

\section{Resultados}

A seguir são apresentados os resultados de cada um dos estudos de caso realizados, e discutida sua contribuição em relação aos objetivos do estudo.

Uma breve descrição dos empreendimentos estudados é apresentada no Quadro 1.

\section{Estudo empírico 1}

O estudo empírico 1 teve características exploratórias, visando a proporcionar maior familiaridade com o aplicativo e com o processo de modelagem BIM 4D para apoio do planejamento da obra. Nele foram simuladas três alternativas de planos de longo prazo e o leiaute de canteiro, empregando BIM 4D, a técnica da linha de balanço e histograma de recursos (Figura 3).

Um dos aspectos relevantes ao processo de modelagem observado durante o estudo foi a importância da prévia definição do objetivo do emprego do BIM 4D. No caso estudado ficou evidente que a execução da obra e o estudo da movimentação dos equipamentos demandam o emprego de modelos distintos, devido às diferenças em termos das escalas de tempo envolvidas em cada uma das situações. 
Quadro 1 - Descrição dos empreendimentos estudados

\begin{tabular}{|l|l|l|l|}
\hline \multicolumn{1}{|c|}{ Estudos } & \multicolumn{1}{c|}{ Fase da obra } & \multicolumn{1}{c|}{ Prazo } & \multicolumn{1}{c|}{ Características dos empreendimentos } \\
\hline $\begin{array}{l}\text { EE1 } \\
\text { Empreendimento L2 }\end{array}$ & $\begin{array}{l}\text { Estrutura e } \\
\text { alvenaria }\end{array}$ & 15 meses & $\begin{array}{l}\text { 12 blocos de 5 pavimentos, com 4 apartamentos } \\
\text { de 2 dormitórios por andar }\end{array}$ \\
\hline $\begin{array}{l}\text { EE2 } \\
\text { Empreendimento L3 }\end{array}$ & $\begin{array}{l}\text { Estrutura e } \\
\text { alvenaria }\end{array}$ & 24 meses & $\begin{array}{l}\text { 2 torres de 19 e 20 pavimentos com } \\
\text { apartamentos de 3 e 4 dormitórios por andar }\end{array}$ \\
\hline $\begin{array}{l}\text { EE3 } \\
\text { Empreendimento M1 }\end{array}$ & Terraplanagem & 20 meses & 514 casas geminadas em condomínio fechado \\
\hline $\begin{array}{l}\text { EE4 } \\
\text { Empreendimento N1 }\end{array}$ & $\begin{array}{l}\text { Terraplanagem e } \\
\text { fundação }\end{array}$ & 24 meses & $\begin{array}{l}\text { 9 torres de 8 pavimentos com 6 apartamentos } \\
\text { de 2 dormitórios por andar }\end{array}$ \\
\hline
\end{tabular}

Figura 3 - Visualização 4D do plano de longo prazo, linha de balanço e histograma de recursos de um dos cenários simulados no estudo 1

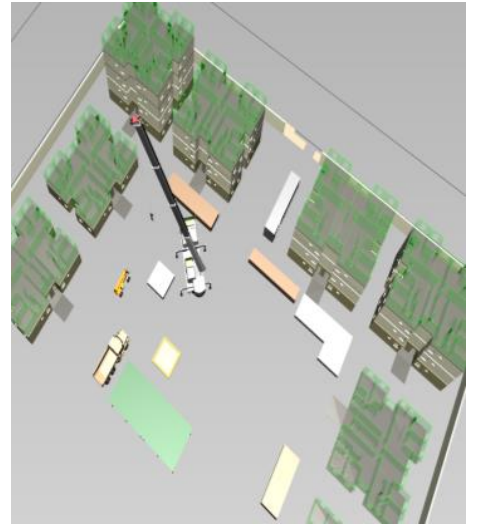

(a) Visualização 4D

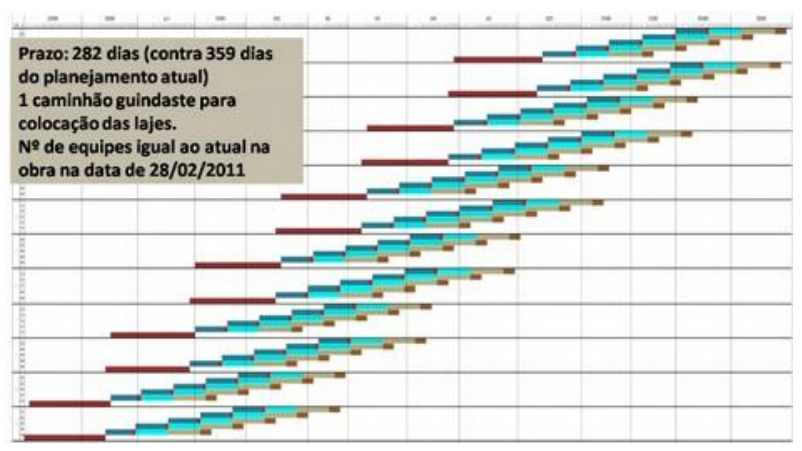

(b) Linha de balanço

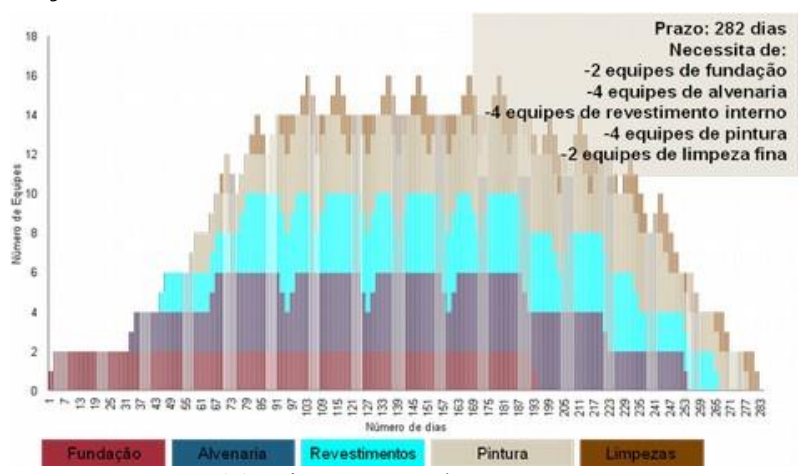

(c) Histograma de recursos

O estudo de caso também permitiu identificar claramente as limitações das técnicas usuais de planejamento no que se refere à identificação de conflitos espaciais envolvendo instalações provisórias, estoques e equipamentos. O emprego da modelagem BIM 4D permitiu identificar diversos conflitos desse tipo, os quais haviam passado despercebidos durante o planejamento da obra e que resultaram em graves problemas durante a execução da obra. A Figura 4 apresenta dois exemplos de conflitos encontrados. Um deles envolvia a ocorrência de um volume excessivamente alto e não previsto no estoque de lajes pré-moldadas (em frente ao bloco A), o que tornou necessária a mudança na sequência de execução da obra como consequência da dificuldade de movimentação do guindaste devido a tais estoques. Outro problema identificado estava relacionado com o descarregamento de paletes de blocos cerâmicos nos pavimentos, o qual foi impossibilitado devido à dissociação do planejamento dos equipamentos de movimentação (no caso, um guindaste com lança telescópica) e dos equipamentos de proteção coletiva (andaimes externos e bandejas de proteção). Tais situações foram identificadas simplesmente pela visualização de algumas operações identificadas como críticas, contribuindo para demonstrar à equipe de planejamento e de obra o potencial da modelagem BIM 4D para prever esse tipo de conflito espacial durante a elaboração do PSP da obra. 
Figura 4 - Identificação de conflitos entre estoques de componentes e movimentação de equipamentos

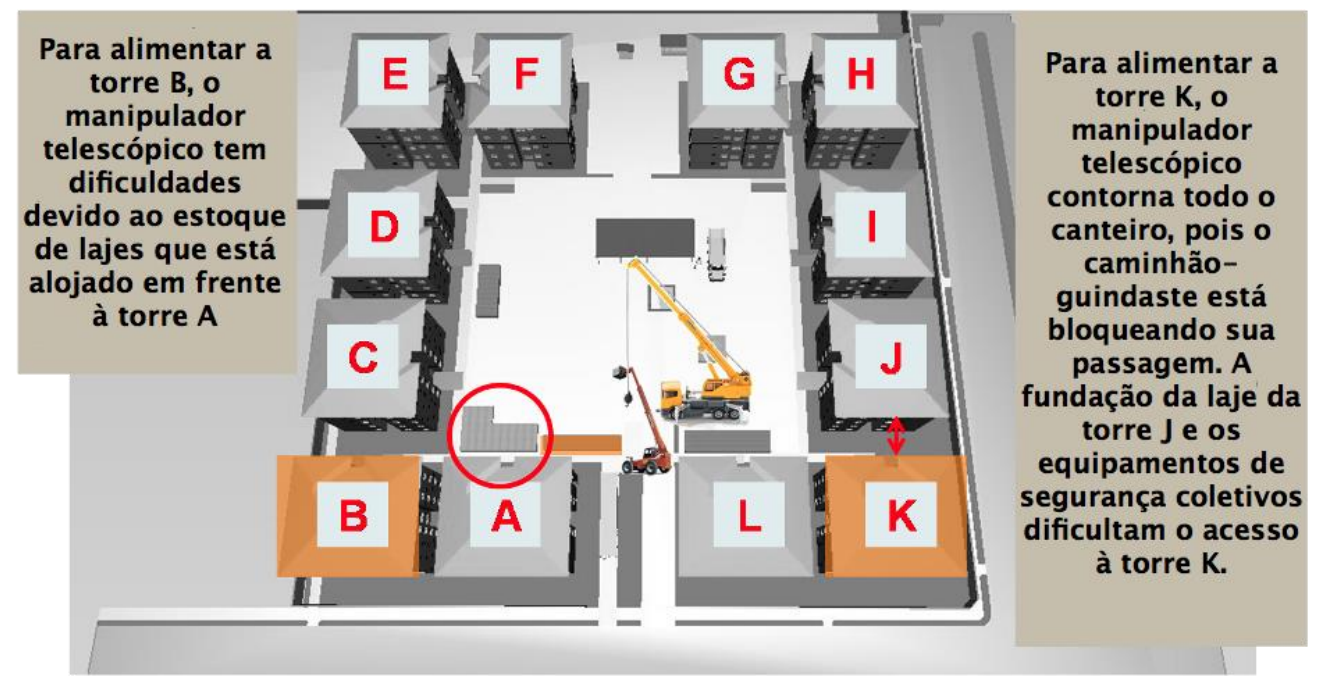

No que diz respeito ao método, a contribuição do EE1 foi confirmar o caráter complementar do emprego da modelagem 4D e de ferramentas tradicionais de planejamento, tais como a LOB e o histograma de mão de obra, para apoiar a tomada de decisão, como sugerido por Björnfot e Jongeling (2007). Nesse contexto, o papel e a contribuição de cada uma dessas ferramentas se deu em um aspecto distinto das demais:

(a) a LOB, em termos dos reflexos quanto ao prazo e à estabilidade na sequência de trabalho;

(b) o histograma de mão de obra, em termos dos custos de mão de obra e capacidade; e

(c) a modelagem BIM 4D, em termos do planejamento espacial.

Como consequência, decidiu-se incorporar o uso simultâneo das três ferramentas ao método proposto.

\section{Estudo empírico 2}

Neste estudo buscou-se simular o planejamento da produção com o uso de modelos BIM 4D, avaliando sua contribuição como suporte à tomada de decisão através do fornecimento de cenários esperados em decorrência de possíveis alternativas de mudança na sequência de ataque de realização do serviço de revestimento externo de fachadas. Esse objetivo atendia a uma demanda da empresa, a qual estudava alternativas para acelerar a conclusão da obra por meio da mudança da sequência de execução do revestimento de fachada, mas tinha receio quanto às implicações das possíveis alternativas para a segurança dos operários (Figura 5). Assim como no EE1, a modelagem BIM 4D foi novamente utilizada em paralelo com a linha de balanço e histograma de mão de obra. $\mathrm{O}$ produto do estudo foi um modelo do processo de modelagem BIM 4D no contexto do PCP.

No tocante ao planejamento da produção, o BIM 4D permitiu visualizar espacialmente a sequência de execução dos serviços, identificando diversas interferências entre eles e as áreas de estoques, acessos e outros elementos do canteiro de obras. Além de auxiliar no planejamento do leiaute da obra e em sua coordenação como o plano de longo prazo, a modelagem 4D permitiu antecipar futuros problemas espaciais envolvendo o abastecimento das torres através do caminhão-guindaste, inclusive identificando obstruções do campo de visão do operador do equipamento que impediriam a operação segura dele.

Com relação ao estudo de replanejamento da sequência de execução do revestimento externo, o uso de BIM 4D possibilitou uma análise em detalhe das implicações dessa mudança quanto às interferências com as demais atividades, bem como o estudo de possíveis alternativas para a fixação de andaimes e avaliação dos riscos dos operários. Com base nos elementos trazidos à tona pelo uso de BIM 4D, a empresa decidiu não implementar as mudanças devido aos riscos à segurança dos operários.

Em ambas as situações ficou evidente que, embora tais decisões digam respeito ao escopo do PSP - o qual deveria ter sido realizado antes do início do empreendimento -, a modelagem 4D pode ser útil caso necessário revisá-lo ou complementá-lo posteriormente, mediante a realização de estudos específicos durante a execução do empreendimento. Isso sugere que o método proposto deve ter características interativas, e a equipe responsável pelo planejamento e controle

88 Biotto, C. N.; Formoso, C. T.; Isatto, E. L. 
da produção não deve apenas analisar os modelos BIM 4D, mas também propor novos cenários de análise ou ajustes nos cenários anteriormente analisados.

No que se refere ao método foi possível identificar a necessidade de considerar mais de um tipo de unidade-base de repetição, de forma a proporcionar diferentes níveis de análise para fins do PSP:

(a) a unidade-base, composta do pavimento-tipo;

(b) o módulo de repetição da unidade-base, composto da torre; e

(c) o empreendimento, incluindo as torres e o espaço em seu entorno.

Com isso, surge também a necessidade de se empregarem diferentes modelos de geometria (modelos 3D) do produto, cada um associado a um desses níveis.

\section{Estudo empírico 3}

O estudo empírico 3 teve como objetivo avaliar o método no contexto do planejamento da produção em empreendimentos horizontais, através da visualização da sequência executiva do empreendimento. $\mathrm{O}$ estudo também contemplou um contexto mais interativo que os estudos anteriores, na medida em que a equipe responsável pela elaboração do PSP foi convidada a sugerir novos cenários para análise ao longo desse processo.

Neste estudo foram elaborados modelos 3D para a unidade-base (composta de um conjunto de duas casas) e para o empreendimento. A partir de um cenário inicial foi elaborada a primeira versão do PSP com o emprego de BIM 4D, LOB e histograma de mão de obra. Foram identificados diversos problemas com a estratégia de ataque inicialmente sugerida. A análise BIM 4D da unidade-base indicou a necessidade de se subordinar o sequenciamento das casas em determinados trechos devido aos aclives existentes, uma vez que duas casas compartilhavam uma mesma parede, demandando que a casa localizada na cota inferior fosse executada antes. Já a modelagem BIM 4D baseada no modelo do empreendimento permitiu identificar interferências que ocorriam entre os serviços repetitivos das casas (que adotavam as casas como unidade-base) e os serviços de terraplanagem (que adotavam quadras como unidade-base) (Figura 6), indicando que a sequência de execução inicialmente proposta apresentava deficiências graves, sendo de difícil execução. Tais análises são necessárias em obras horizontais que envolvem a execução de serviços de infraestrutura.

A partir dessas dificuldades foram sugeridos dois cenários alternativos pela equipe de planejadores, as quais diferiam entre si basicamente em termos da sequência de execução adotada. No estudo comparativo dessas alternativas, o uso de BIM 4D foi especialmente útil não somente para verificar as interferências entre os serviços, mas também para visualizar espacialmente o grau de concentração deles no canteiro de obras, o que afeta diretamente a necessidade de transportes e movimentações na obra. Essa foi uma significativa contribuição do estudo de caso quanto aos benefícios do uso do BIM 4D na elaboração do PSP quando se trata de empreendimentos horizontais.

Em termos do método, a principal contribuição do estudo de caso foi integrar o método de elaboração do PSP com BIM 4D ao processo de planejamento de longo prazo do empreendimento, provendo características de interatividade ao processo.

\section{Figura 5 - Estudo do replanejamento do reboco de fachada de uma das torres no estudo 2}

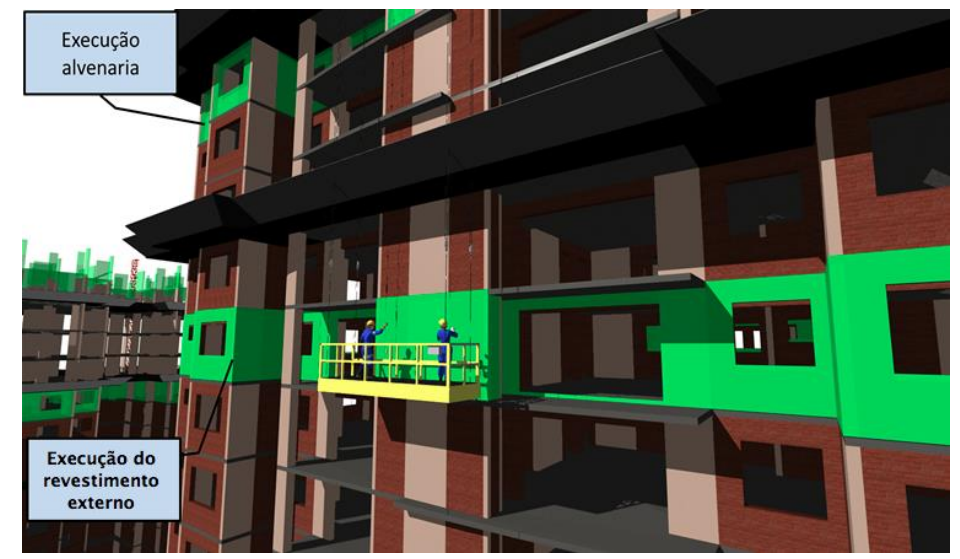


Figura 6 - Visualização 4D com radiers iniciando-se sem o serviço de terraplanagem concluído

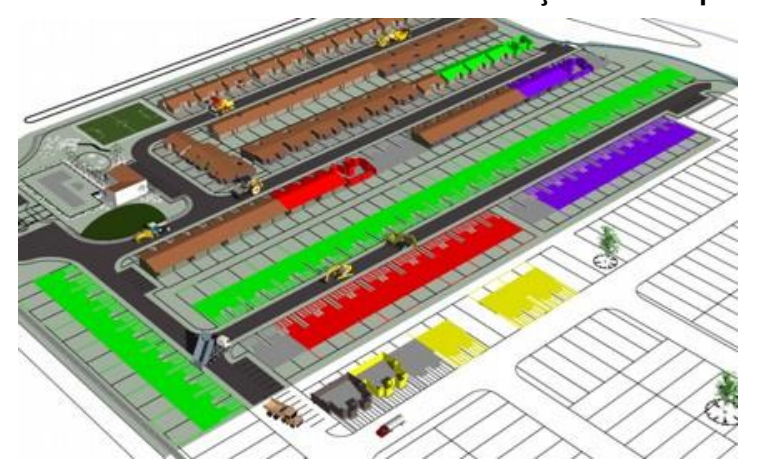

\section{Estudo empírico 4}

O foco deste estudo foi a elaboração do PSP junto com os participantes da empresa, partindo de um conjunto de cenários propostos pela empresa em função do ritmo de vendas do empreendimento e da disponibilidade de mão de obra. Mais do que identificar a melhor alternativa para determinado cenário, a empresa desejava avaliar quais das alternativas seriam menos vulneráveis a tais variações.

Nesse estudo, o escopo do PSP com BIM 4D foi bem mais amplo que nos demais, incluindo o empreendimento, os equipamentos de movimentação, os elementos do canteiro de obras, tais como áreas de estoque, vias de acesso e instalações provisórias, e os equipamentos de proteção coletiva. Isso demandou a utilização de diversos modelos geométricos (3D) - da unidadebase (pavimento-tipo); do módulo de repetição da unidade-base (prédios); e do empreendimento -, bem como a inclusão de equipamentos, elementos do canteiro de obras e equipamentos de proteção coletiva (bandejas de proteção). As Figuras 7 e 8 ilustram o uso da visualização BIM 4D para o estudo de alternativas de equipamentos de transporte vertical e da localização de áreas de estoques.

Além de servir às análises mencionadas, o modelo BIM 4D foi também utilizado para o projeto das bandejas de segurança (detalhamento), na contratação da instalação dos elevadorescremalheiras e como forma de facilitar a comunicação do planejamento aos subempreiteiros da obra.

A principal contribuição do estudo para o método foi proporcionar uma avaliação do método quanto à extensão de seu escopo, incluindo simultaneamente diversos elementos da construção e do canteiro de obra.

\section{Descrição do método proposto}

A Figura 9 apresenta o método proposto, o qual é composto de três etapas:

(a) etapa de preparação;

(b) etapa de elaboração de cenários; e

(c) etapa de simulação 4D e análise dos resultados.

\section{Etapa de preparação}

A etapa de preparação ocorre apenas uma única vez na empresa envolvida na implantação do método, embora seja possível que algumas decisões necessitem ser revisadas quando do início de um novo empreendimento, de forma a atender a necessidades específicas dele.

Esta etapa deve iniciar-se pela definição dos usuários dos modelos BIM 4D. Como se trata de um método para apoiar a tomada de decisão na gestão do sistema de produção, os prováveis usuários são os mestres, engenheiros de obras, engenheiros de planejamento e coordenadores de obras ou gerentes de produção, podendo sua utilização ser estendida a fornecedores, clientes, operários, entre outros. O método proposto foi baseado nos estudos cujos clientes eram os engenheiros das obras e de planejamento.

Após a identificação do usuário do modelo, definese o escopo da modelagem (por exemplo, incluir ou não os equipamentos de proteção coletiva). Deve-se especificar o nível de desenvolvimento do sistema de produção a ser estudado, assim como as unidades de análise a serem consideradas: unidadebase, empreendimento e canteiro de obras. É importante frisar que o método foi desenvolvido principalmente como resultado de estudos aplicados na fase de projeto de sistemas de produção e de planejamento de longo prazo da obra. Porém, devido ao caráter oportunístico do planejamento, em alguns estudos foi necessário antecipar informações e, para isso, detalhar mais

90 Biotto, C. N.; Formoso, C. T.; Isatto, E. L. 
alguns pacotes de trabalho, no nível típico de planos de médio de prazo. Assim, o nível de desenvolvimento dos modelos BIM 3D depende não somente do escopo da modelagem, mas também do nível de planejamento e controle no qual o modelo está sendo utilizado.

Figura 7 - Localização das áreas de estoque, elevadores cremalheiras e caminhão-guindaste

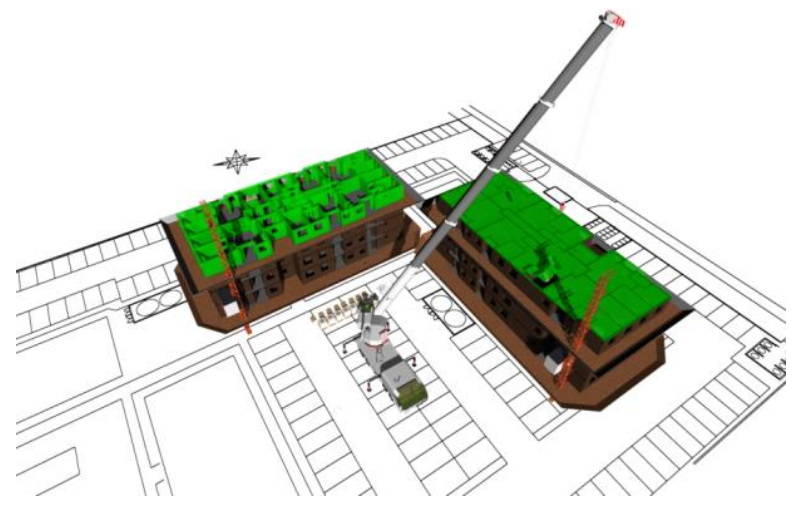

Figura 8 - No caso de uso de elevador-cremalheira, o processo de cura de um segmento do pavimento inviabiliza o acesso ao outro segmento

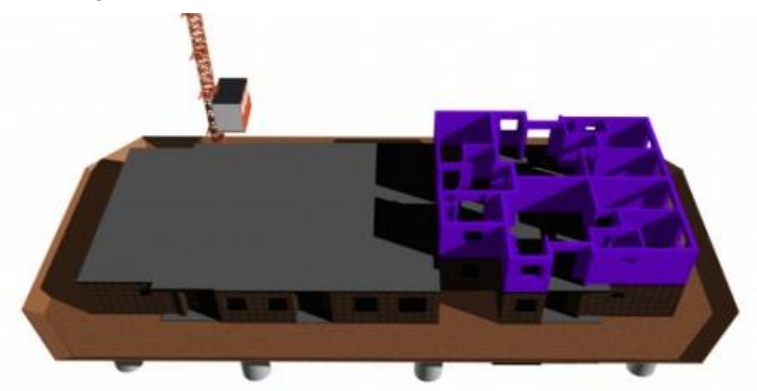

Figura 9 - Método para o uso da modelagem BIM 4D no apoio à tomada de decisão na gestão do sistema de produção de empreendimentos de construção

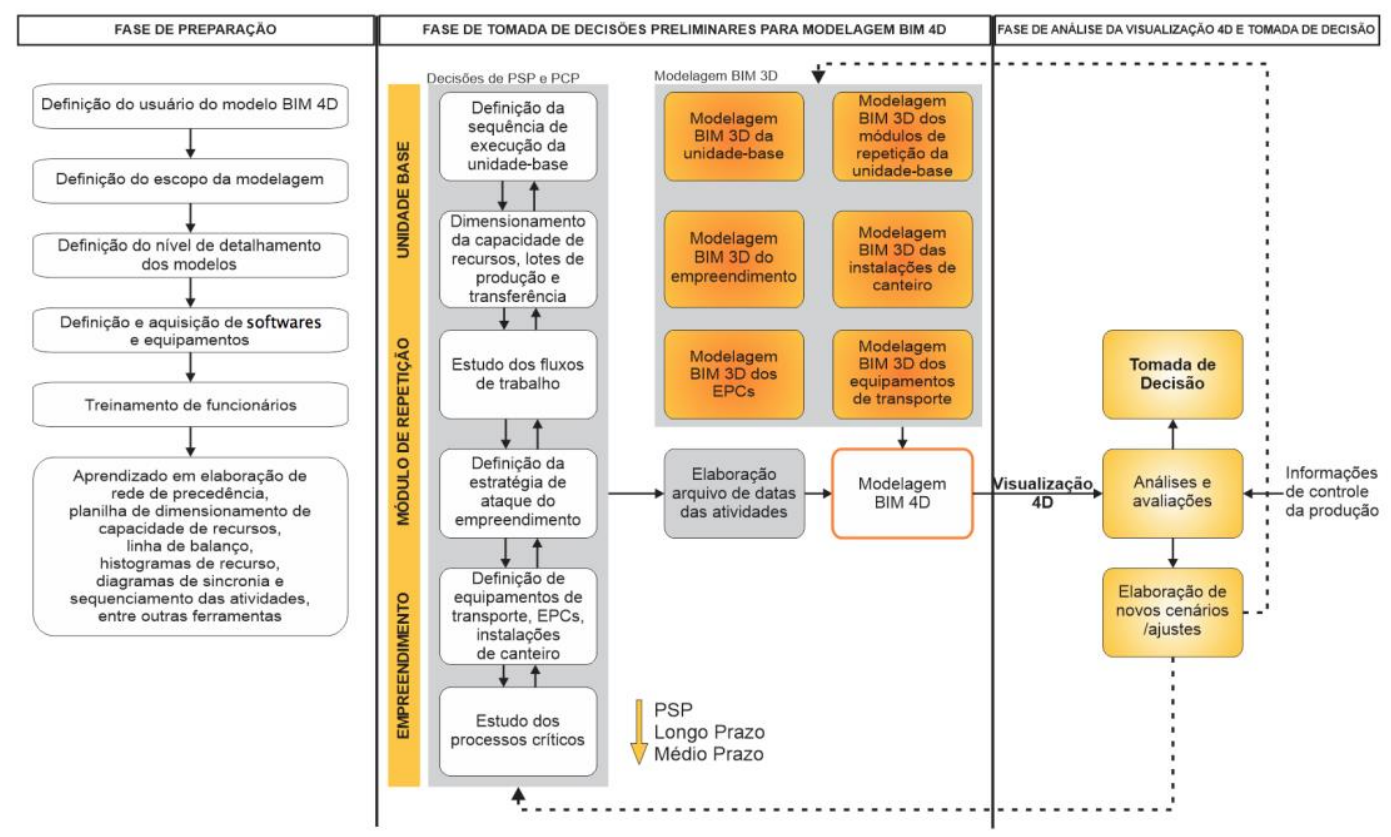


Uma vez definido o escopo do trabalho, pode-se então escolher e adquirir computadores e os programas necessários à modelagem BIM 4D e definir as necessidades de treinamento da equipe no uso desses programas.

Por fim, os funcionários envolvidos na gestão do sistema de produção devem ter conhecimento acerca de outras ferramentas de planejamento e controle, utilizadas em conjunto com a modelagem BIM 4D, tais como redes de precedência, planilha de dimensionamento de capacidade de recursos, linha de balanço, histogramas de recurso, diagramas de sincronia e sequenciamento das atividades.

\section{Etapa de elaboração dos cenários}

A etapa de elaboração dos cenários consiste em preparar as informações de entrada para a modelagem 4D, incluindo as unidades de análise a serem adotadas, as escalas de tempo e a definição do escopo das decisões a serem tomadas.

No método desenvolvido nesta pesquisa, duas unidades de análise foram trazidas do modelo proposto por Schramm, Costa e Formoso (2006): a unidade-base e o empreendimento. No presente estudo, porém, identificou-se a necessidade de incorporar uma nova unidade de análise: o módulo de repetição da unidade-base, correspondendo às torres (estudo empírico 2), quadras de casas (estudo empírico 3) e blocos de apartamentos (estudo empírico 4).

Nos aplicativos 4D há a possibilidade de empregar diferentes escalas de tempo: horas, semanas, meses e anos. Esse mecanismo é importante quando se deseja modelar em uma escala de longo prazo eventos de curta duração. Por exemplo, a movimentação de caminhões emprega escala de minutos ou até mesmo de horas, enquanto a execução de uma atividade como alvenaria emprega escala de dias. Logo, se o modelador 4D projetar a movimentação detalhada dos caminhões, sua visualização na escala de execução do empreendimento como um todo (com duração de meses) seria muito breve na escala temporal, dificultando a visualização. Porém, se for de interesse do modelador projetar os processos críticos, pode-se modelar toda a operação em uma mesma escala temporal, de forma que a cena estudada tenha a mesma grandeza temporal.

Em relação ao escopo de decisões a serem tomadas, a Figura 9 inclui todas as categorias de decisão propostas pelo modelo de Schramm, Costa e Formoso (2006) para o PSP. Entretanto, outras decisões podem ser consideradas no escopo do trabalho, conforme indicado também na Figura 9: definição dos equipamentos de transporte vertical, análise de interferências de equipamentos de proteção coletiva e instalações do canteiro, planejamento da logística e leiaute do canteiro de obras. Em alguns casos poderiam ser utilizados softwares de clash detection. Tais categorias de decisão adicionais foram aquelas identificadas com base nos quatro estudos realizados, não se pretendendo com isso cobrir todas as possíveis categorias a serem analisadas.

Quando a modelagem 4D é utilizada para apoiar a tomada de decisão no PSP, as várias categorias de decisão devem ser consideradas de forma conjunta, uma vez que tais decisões devem ser interdependentes (SCHRAMM; COSTA; FORMOSO, 2006), o que recomenda que o modelo não deve ser demasiadamente detalhado. Nesse caso, o uso de BIM 4D deverá ocorrer no início do empreendimento, quando da realização do PSP.

Já no âmbito do PCP, os estudos realizados empregando a modelagem 4D são mais específicos e detalhados que os do PSP, visando a revisar ou a complementar decisões tomadas no início do empreendimento, quando da realização do PSP. O modelo $4 \mathrm{D}$ pode ser utilizado não somente para visualizar a sequência de execução de atividades, mas também para visualizar outras decisões tomadas no PSP ou PCP, tais como leiaute do canteiro, tamanho e distância entre lotes de produção e posicionamento de equipamentos. Em algumas situações esses estudos serão originados a partir de demanda da obra, em função de problemas surgidos (tais como atrasos da obra, risco de acidentes, interferência entre equipes ou equipamentos), o que poderá implicar modelos com maior nível de detalhes ou que incluam detalhes específicos, exigindo maior interação entre o modelador e os tomadores de decisão para a elaboração dos cenários.

\section{Etapa de simulação 4D e análise dos resultados}

A etapa de criação dos modelos 3D inclui a elaboração de diversos tipos de modelos segundo seu conteúdo e abrangência, dependendo do escopo desejado.

No que se refere à abrangência, os modelos devem guardar correspondência com as unidades de análise empregadas. Assim, é inicialmente necessário mais de um modelo 3D, cada um contemplando uma unidade de análise distinta.

O conteúdo de todos esses tipos de modelo consiste na edificação ou em partes da mesma. Porém, dado que a utilização de BIM 4D permite

92 Biotto, C. N.; Formoso, C. T.; Isatto, E. L. 
que outras decisões sejam incluídas no escopo do PSP para análise integrada, modelos contemplando outros tipos de conteúdo podem ser incluídos no modelo BIM 4D: os equipamentos de transporte, os equipamentos de proteção coletiva e as instalações do canteiro.

A elaboração desses modelos vai depender, em grande parte, de decisões já tomadas relativas ao PSP. Por exemplo, as decisões quanto aos lotes de transferência e produção definirão a forma como os objetos serão segmentados quando da criação dos modelos 3D.

A partir da visualização $4 \mathrm{D}$, pode-se avaliar a necessidade de ajustes no modelo, no arquivo de datas, ou a elaboração de novas alternativas e cenários do sistema de produção. É nesta fase que as decisões serão tomadas com o auxílio dos modelos 4D. Com base nessas decisões, tanto aspectos específicos do PSP como os planos de longo prazo anteriormente elaborados poderão ser revistos, podendo resultar na necessidade de novas simulações. Se a obra estiver em andamento, informações relacionadas ao controle da obra devem ser consideradas na revisão dos modelos 4D. Alterações também podem se fazer necessárias nos modelos $3 \mathrm{D}$, de forma a refletir mudanças no nível de detalhe do projeto.

\section{Conclusões}

Neste trabalho foi proposto um método para a modelagem BIM 4D para apoiar a tomada de decisões no projeto e planejamento de sistemas de produção na construção civil, com foco em empreendimentos habitacionais de baixa renda. Este estudo investigou a inserção do BIM 4D no contexto organizacional, relacionando a modelagem a um conjunto de categorias de decisão relevantes na gestão da produção.

Como contribuições desta pesquisa destacam-se:

(a) a necessidade de considerar diferentes unidades de análise da modelagem, pelo caráter repetitivo das obras neste segmento de mercado;

(b) a ampliação do escopo da modelagem, que inclui não somente sequência de execução da obra (atividades que agregam valor), mas também equipamentos de movimentação de materiais e pessoas, equipamentos de proteção coletiva, instalações provisórias, entre outros; e

(c) o uso combinado dos modelos BIM 4D com outras ferramentas de planejamento e controle, tais como linha de balanço e histograma de mão de obra.

Outro objetivo que se alcançou nesta pesquisa foi o de identificar os benefícios e as dificuldades de se utilizar a modelagem BIM 4D nos processos de projeto e planejamento dos sistemas de produção. Nesse sentido, foram identificados cenários de utilização dos modelos BIM 4D para apoiar a tomada de decisão nos referidos processos. Por exemplo, no PSP é recomendado o uso de BIM 4D no início do empreendimento, e os modelos não devem ser muito detalhados em função da pouca disponibilidade de informações. Por outro lado, no PCP os modelos 4D devem ser mais detalhados e voltados a usos específicos, tais como o estudo de processos críticos e o detalhamento do leiaute do canteiro. Uma decisão crucial na construção desses modelos é o conteúdo (conjunto de objetos e respectivos atributos) a ser incluído neles, como equipamentos de transporte, equipamentos de proteção coletiva, estoques, entre outros. É importante avaliar cuidadosamente as demandas dos usuários dos modelos $4 \mathrm{D}$, de forma a evitar um esforço desnecessário de detalhamento dos modelos.

Os principais benefícios trazidos pela modelagem BIM 4D foram: aumentar a comunicação e o entendimento das decisões entre os participantes; entender as inter-relações entre as decisões da gestão da produção, principalmente no PSP; e permitir a simulação de vários cenários alternativos de forma rápida.

O estudo apontou algumas limitações da modelagem 4D, principalmente no que se refere à visualização de alterações no fluxo de trabalho, sendo difícil enxergar os serviços internos das edificações, e às diferenças entre os prazos de execução dos empreendimentos. Portanto, existem limitações no uso dessa tecnologia para definir ritmos de produção e promover o fluxo contínuo das atividades e ininterrupto das equipes, o que torna seu uso obrigatoriamente dependente de outras ferramentas que também permitam a visualização de algumas decisões de projeto e planejamento dos sistemas de produção.

A partir da realização deste trabalho emergiram algumas sugestões de estudos aprofundados:

(a) refinar e testar o modelo, através de sua aplicação em outros empreendimentos;

(b) acrescentar outras dimensões na análise das simulações, tais como custos;

(c) investigar o grau de desenvolvimento de modelos BIM 4D de um empreendimento para diferentes clientes (investidores, clientes, fornecedores, entre outros); e

(d) desenvolver ambientes digitais que possam vincular automaticamente algumas ferramentas de planejamento e controle, tais como linha de 
balanço, diagramas de sincronia e sequenciamento, e histograma de recursos aos modelos BIM 4D.

\section{Referências}

\section{ASSOCIATED GENERAL CONTRACTORS OF} AMERICA. The Contractors' Guide to BIM. Disponível em: 〈www.agc.org>. Acesso em: 20 nov. 2011.

ARDITI, D.; TOKDEMIR, O. B.; SUH, K. Challenges in Line-of-Balance Scheduling. Journal of Construction Engineering and Management, v. 128, n. 6, p. 545-556, 2002.

BACCARINI, D. The Concept of Project Complexity: a review. International Journal of Project Management, v. 14, n. 4, p. 201-204, 1996.

BALLARD, G.; HOWELL, G. Shielding Production: an essential step in production control. Technical Report No. 97-1. Construction Engineering and Management Program, Department of Civil and Environmental Engineering, University of California, 1998.

BALLARD, G. The Last Planner System of Production Control. 2000. Tese (Doutorado) Birmingham: Faculty of Engineering, The University of Birmingham, 2000.

BALLARD, G. et al. Production System Design in construction. In: ANNUAL CONFERENCE OF THE INTERNATIONAL GROUP FOR LEAN CONSTRUCTION, 9., Singapore, 2001.

Proceedings... Singapore: IGLC, 2001.

BARISON, M. B.; SANTOS, E. T. BIM Teaching: Current International Trends. Gestão \& Tecnologia de Projetos, v. 6, n. 2, p. 67-80, 2012.

BENJAORAN V.; BHOKHA S. Enhancing Visualization of 4D CAD Model Compared to Conventional Methods. Engineering, Construction and Architectural Management, v. 16, n. 4, p. 392-408, 2009.

BJÖRNFOT, A.; JONGELING, R. Application of Line of Balance and 4D CAD for Lean Planning. Construction Innovation, v. 7, n. 2, p.200-211, 2007.

CHECCUCCI, E. S. ; PEREIRA, A. P. C.; AMORIM, A. L. Difusão e Apropriação do Pparadigma BIM no Brasil. Gestão \& Tecnologia de Projetos, v. 1, n. 1, p. 19-39, 2013.

CHOI, B. et al. Framework for Work-Space Planning Using Four-Dimensional BIM in Construction Projects. Journal of Construction Engineering and Management, v. 9, n. 140, 2014.
COBLE, R. J.; BLATTER, R. L.; AGAJ, I. Application of 4D CAD in the Construction Workplace. In: ISSA, R. R.; FLOOD, I.; O'BRIEN, W. J. 4D CAD and Visualization in Construction: developments and applications. Lisse/Abingon/Exton (PA): A. A. Balkema Publishers, 2005.

COLLIER, E.; FISCHER, M. Four-Dimensional Modeling in Design and Construction. CIFE Technical Report \# 101. Stanford, CA: Stanford University, 1995.

EADIE, R. et al. An Analysis of the Drivers For Adopting Building Information Modelling. Journal of Information Technology in Construction, v. 18, p. 338-352, 2013.

EASTMAN, C. et al. BIM Handbook: a guide to building information modeling for owners, managers, designers, engineers, and contractors. 2 . ed. New Jersey: John Wiley \& Sons, 2011.

FISCHER, M.; HAYMAKER, J.; LISTON, K. Benefits of 3D and 4D Models for Facility Managers and AEC Service Providers. In: ISSA, R. R.; FLOOD, I.; O'BRIEN, W. J. 4D CAD and Visualization in Construction: developments and applications. Lisse/Abingon/Exton (PA): A. A. Balkema Publishers, 2005.

GAITHER, N.; FRAZIER, G. Administração da Produção e Operações. 8. ed. São Paulo: Pioneira Thomson Learning, 2001.

GENERAL SERVICES ADMINISTRATION. GSA Building Information Modeling Guide Overview. United States: GSA, 2007. Series 01.

HAYMAKER, J.; FISCHER, M. Challenges and Benefits of 4D Modeling on the Walt Disney Concert Hall Project. CIFE Working Paper \#064. Stanford, CA: Stanford University, 2001.

KASANEN, E.; LUKKA, K.; SIITONEN, A. The Constructive Approach in Management Accounting. Journal of Management Accounting Research, v. 5, p. 243-264, fall 1993.

KHATIB, J. M.; CHILESHE, N.; SLOAN, S. Antecedents and Benefits of 3D and 4D Modelling For construction Planners. Journal of Engineering, Design and Technology, Bingley, p. 159-172, 2007.

KOSKELA, L. An Exploration Towards a Production Theory and Its Application to Construction. Espoo, 2000. Tese (Doutorado) Espoo, Finlândia: Technical Research Centre of Finland, 2000. 
KOSKELA, L.; BALLARD, G. What Should We Require From a Production System in Construction? Journal of Construction Research, p. 1-8, 2003.

KUNZ, J.; FISCHER, M. Virtual Design and Construction: themes, case studies and implementation suggestions. CIFE Working Paper \#097. Stanford, CA: Stanford University, 2011.

KYMMELL, W. Building Information Modeling: planning and managing construction projects with 4D CAD and simulations. New York: McGraw-Hill, 2008.

LAUFER, A.; TUCKER, R. L. Is Construction Project Planning Really Doing Its Job? A critical examination of focus, role and process. Construction Management and Economics, New York, v. 5, n. 3, p. 243-266, jan. 1987.

LEITE, F. et al. Analysis of Modeling Effort and Impact of Different Levels of Detail in Building Information Models. Automation in Construction, v. 20, n. 5, p. 601-609, 2011.

LUKKA, K. The Constructive Research Approach. In: OJALA, L.; HILMOLA, O-P. (Eds.). Case Study Research in Logistics.. Turku: Turku School of Economics and Business Administration, 2003. Series B1. P. 83-101

MARCH, S. T.; SMITH, G. F. Design and Natural Science Research on Information Technology. Decision Support Systems, v. 15, n. 4, p. 251266, 1995.

MCGRAW HILL CONSTRUCTION. The Business Value of BIM For Construction in Major Global Markets: how contractors around the world are driving innovation with building information modeling. Bedford, MA: McGrawHill, 2014.

MEREDITH, J. R.; SHAFER, S. M. Administração da Produção Para MBAs. Porto Alegre: Bookman, 2002.

MESSNER, J. et al. BIM Project Execution Planning Guide. The Computer Integrated Construction Research Program (CIC), Penn State University, 2010.

PAPAMICHAEL, K. Application of Information Technologies in Building Design Decisions.

Building Research \& Information, v. 27, n. 1, p. 20-34, 1999.
RILEY, D. The Role of 4D Modeling in Trade Sequencing and Production Planning. In: ISSA, R. R.; FLOOD, I.; O'BRIEN, W. J. 4D CAD and Visualization in Construction: developments and applications. Lisse/Abingon/Exton (PA): A. A. Balkema Publishers, 2005.

RISCHMOLLER, L.; ALARCÓN, L. F. 4D-PS: putting and IT new work process into effect. In: INTERNATIONAL CONFERENCE CIB W78, Denmark, 2002. Proceedings... Denmark: Distributing Knowledge in Building, 2002.

RODRIGUES, A. A. O Projeto do Sistema de Produção no Contexto de Obras Complexas. Porto Alegre, 2006. Dissertação (Mestrado em Engenharia Civil) - Programa de Pós-Graduação em Engenharia Civil, Universidade Federal do Rio Grande do Sul, Porto Alegre, 2006.

RUSCHEL, R. C. Editorial: modelagem da informação da construção. PARC Pesquisa em Arquitetura e Construção, Campinas, v. 5, n. 1, p. 3-5, jan./jun. 2014.

RUSCHEL, R. C.; ANDRADE, M. L. V. X.; MORAIS, M. O Ensino de BIM no Brasil: onde estamos? Ambiente Construído, Porto Alegre, v. 13, n. 2, p. 151-165, abr./jun. 2013.

SACKS, R.; RADOSAVLJEVIC, M.; BARAK, R. Requirements For Building Information Modeling Based Lean Production Management Systems For Construction. Automation in Construction, v. 19, n. 5, p. 641-655, 2010.

SCHRAMM, F. K.; COSTA, D. B.; FORMOSO, C. T. O Projeto do Sistema de Produção na Gestão de Empreendimentos Habitacionais de Interesse Social. Ambiente Construído, Porto Alegre, v. 6, n. 2, p. 59-74, abr./jun. 2006.

SCHRAMM, F. K. Projeto de Sistemas de Produção na Construção Civil Utilizando Simulação Computacional Como Ferramenta de Apoio à Tomada de Decisão. Porto Alegre, 2009. Tese (Doutorado em Engenharia Civil) Programa de Pós-Graduação em Engenharia Civil, Universidade Federal do Rio Grande do Sul, Porto Alegre, 2009.

WEBB, R. M.; HAUPT, T. C. The Potential of 4D CAD as Tool For Construction Management. In: ISSA, R. R.; FLOOD, I.; O'BRIEN, W. J. (Eds.). 4D CAD and Visualization in Construction: developments and applications. Lisse/Abingon/Exton (PA): A. A. Balkema Publishers, 2005.

ZHOU, W. et al. An Interactive Approach to Collaborative 4D Construction Planning. Journal of Information Technology in Construction, v. 14, p. 30-47, mar. 2009. 


\section{Clarissa Notariano Biotto}

SIPPRO - Soluções de Planejamento da Produção | Av. Padre Antônio Tomás, 2420, sala 605, Aldeota | Fortaleza - CE - Brasil | CEP 60140-160 | Tel.: (85) 3244-1697 | E-mail: clerwice@gmail.com

\section{Carlos Torres Formoso}

Programa de Pós Graduação Em Engenharia Civil, Núcleo Orientado Para a Inovação da Edificação | Universidade Federal do Rio Grande do Sul | Av. Osvaldo Aranha 99, $3^{\circ}$ andar, Bom Fim | Porto Alegre - RS - Brasil | CEP 90035-190 | Tel.: (51) 3308-3518 |

E-mail: formoso@ufrgs.br

\section{Eduardo Luis Isatto}

Escola de Engenharia, Núcleo Orientado Para a Inovação da Edificação | Universidade Federal do Rio Grande do Sul | Av. Osvaldo Aranha, 99, Prédio Castelinho, Centro | Porto Alegre - RS - Brasil | CEP 90035-190 | Tel.: (51) 3308-3959 | E-mail: isatto@ufrgs.br

\section{Revista Ambiente Construído}

Associação Nacional de Tecnologia do Ambiente Construído

Av. Osvaldo Aranha, $99-3^{\circ}$ andar, Centro

Porto Alegre - RS - Brasil

$$
\text { CEP } 90035-190
$$

Telefone: +55 (51) 3308-4084

Fax: +55 (51) 3308-4054

www.seer.ufrgs.br/ambienteconstruido

E-mail: ambienteconstruido@ufrgs.br

96 Biotto, C. N.; Formoso, C. T.; Isatto, E. L. 